\title{
EVOLUÇÃO CRUSTAL DO BLOCO SÃO ROQUE, NA REGIẤO SUDESTE DO ESTADO DE SÃO PAULO
}

\author{
PETER C. HACKSPACHER*, ANTÔNIO M. GODOY* E MARCOS A.F. OLIVEIRA*
}

\begin{abstract}
CRUSTAL EVOLUTION OF SÃO ROQUE BLOCK IN THE SOUTHEASTERN REGION OF SÃO PAULO STATE. Field mapping in the region between Itu, Cabreuva and Pirapora do Bom Jesus $\mathrm{SP}$, an area of $3.000 \mathrm{~km}^{2}$, has added much to our understanding of late Proterozoic histories in São Paulo State, especially in the São Roque block, between the Itu - Jundiuvira and Taxaquara shear zones. Mapping of the adjacent Jundiai and Embu blocks also contributed importantly. Some of the principal conclusions include: (i) an initial extension of the Transamazonian crust around $1.8 \mathrm{Ga}$, with sedimentation and volcanism of the Serra do Itaberaba and São Roque groups; (ii) assuming an eastward dipping A-Type subduction during the Brazilian/Panafrican Cycle, mere was a collision with an initial Dn $+1 /+2$ deformation, with sub-horizontal foliation and northwest/northeast vergence; (iii) $\mathrm{Dn}+3$ deformation, was observed in the lithologies of the Itapira Complex, Serra do Itaberaba and São Roque groups and related igneous rocks. Based largely on the interpretation of the $\mathrm{Dn}+3$ deformation, there was an initial transtensional regime with emplacement of Brazilian granites followed by a transcurrent/transpressional regime. This transcurrent/transpression regime produced normal folds and vertical mylonitic foliations in the shear zones, especially near the limits of the blocks. A later, brittle tectonic phase with a northeast-southwest trend also exists, in the Sorocaba Massif.
\end{abstract}

Keywords: São Roque Group, Brazilian Orogenesis, transtensional and transpressional regimes.

\begin{abstract}
RESUMO O mapeamento geológico realizado nas proximidades das cidades de Itu, Cabreúva e Pirapora do Bom Jesus - SP permitiu reconhecer feicões estruturais, metamórficas e magmáticas relacionadas à história pré-cambriana presente nos blocos Jundiaí, São Roque e Embu. A partir das informações obtidas no Bloco São Roque, entre as zonas de cisalhamentp Itu-Jundiuvira e Taxaquara, reconheceu-se uma estruturação a partir de uma distensão da crosta Transamazônica por volta de 1,8 Ga, com sedimentação e vulcanismo dos Grupos Serra do Itaberaba e São Roque. Assumindo uma subducção tipo A Brasiliana/Panafricana com mergulho para E, estabeleceu-se uma colisão com deformação $\mathrm{Dn}+1 /+2$ inicial, com foliação suborizontal e vergência, ora para noroeste, ora para nordeste. Segue-se a fase de deformação principal Dn+3, de orientação NE-SW, registrada nas litologias do Complexo Itapira, Grupos Serra do Itaberaba/São Roque e nas rochas ígneas associadas. A esta fase relacionam-se regimes que vão desde transtensivo, associado à colocação dos granitos brasilianos, até transcorrente/transpressivo, com formação de dobras normais e com foliação milonítica vertical nas zonas de cisalhamento, principalmente junto aos limites de blocos. Uma tectônica rúptil oblíqua mais tardia, com direção NE-SW, é observada principalmente no Maciço Granitóide Sorocaba, através da exposição lateral de blocos de diferentes níveis crustais.
\end{abstract}

Palavras-chave: Grupo São Roque, Orogênese Brasiliana, regimes transtensionais e transpressionais.

INTRODUÇÃO A partir de levantamentos geológicos, estudos petrográficos e estruturais realizados nas rochas metassedimentares, ortoderívadas e nos granitóides situados nas Folhas São Roque e Cabreúva 1:50.000, bem como nas Folhas Moreira, Cabreúva, Japí, Araçariguama, Sorocaba, Brigadeiro Tobias e Sanandúva, em 1:25.000, além de informações de regiões circunvizinhas (Fig. 1), fez-se uma reconstrução do quadro geológico dentro do domínio do Bloco São Roque (Hasui et al 1969).

Pretendeu-se, com o levantamento das folhas citadas, resgatar dados que pudessem auxiliar na reconstrução de uma história geológica que associasse a tectônica, o metamorfismo e o alojamento de rochas plutônicas dentro de uma história progressiva relacionada ao final do processo orogênico brasiliano.

Sobre um embasamento, representado pelo Complexo Itapira, exposto a norte da Zona de Cisalhamento Itú-Jundiuvira (Hackspacher et al. 1991a), depositou-se, há aproximadamente 1,8 Ga (Tassinari et al. 1988), a seqüência metavulcanossedimentar referente aos Grupos Itaberaba e São Roque, seguida de evolução tectono-metamórfica durante o Ciclo Brasiliano (Tassinari 1988), com a possibilidade de evento orogênico no Proterozóico Médio (Tassinari et al 1985).

Segundo a óptica de uma colisão Brasiliana/Panafricana do tipo A, com subducção para E (Neves \& Cordani 1991), temos um intenso sistema de cisalhamentos transcorrentes e uma grande expressão de rochas plutônicas de idades semelhantes, com complexa evolução magmática, com a presença das rochas granitóides com trends químicos cálcio-alcalinos, peraluminosos e metaluminosos, seguidas tardiamente pelas suítes subalcalinas a alcalinas colocadas em condições de epizona.

GEOLOGIA DA ÁREA O embasamento na área estudada é constituído por rochas gnáissico-migmatíticas, metassedimentos pelíticos e psamíticos plataformais intercalados com vulcânicas básicas (Santoro 1984), designado como Complexo Itapira por Batista et al (1986), Oliveira et al (1986), Hackspacher et al (1988), ou Grupo Amparo por Hasui et al (1978) e Santoro (1984), a norte da Zona de Cisalhamento Itu-Jundiuvira, e possivelmente como Complexo Embu, a sul da Zona de Cisalhamento Taxaquara. A história tectono-metamórfica está relacionada possivelmente ao Proterozóico Inferior ou mais antigo (Artur 1988, Tassinari et al 1988) e retrabalhado posteriormente, durante a orogênese brasiliana. Próximo à cidade de Cabreúva tais unidades litológicas podem ser empilhadas obedecendo critérios estratigrảificos, apesar da tectônica de cavalgamento que destrói parcialmente a maior parte dos contatos primários. Na base ocorrem granada-biotita xistos, gonditos e anfibolitos da Formação Ermida (Hasui et al 1978), parcial-

\footnotetext{
* Departamento de Petrologia e Metalogenia, Instituto de Geociências e Ciência Exatas, Universidade Estadual Paulista, Avenida 24-A, ISIS, CEP 13506-900, Rio Claro, São Paulo, Brasil
} 


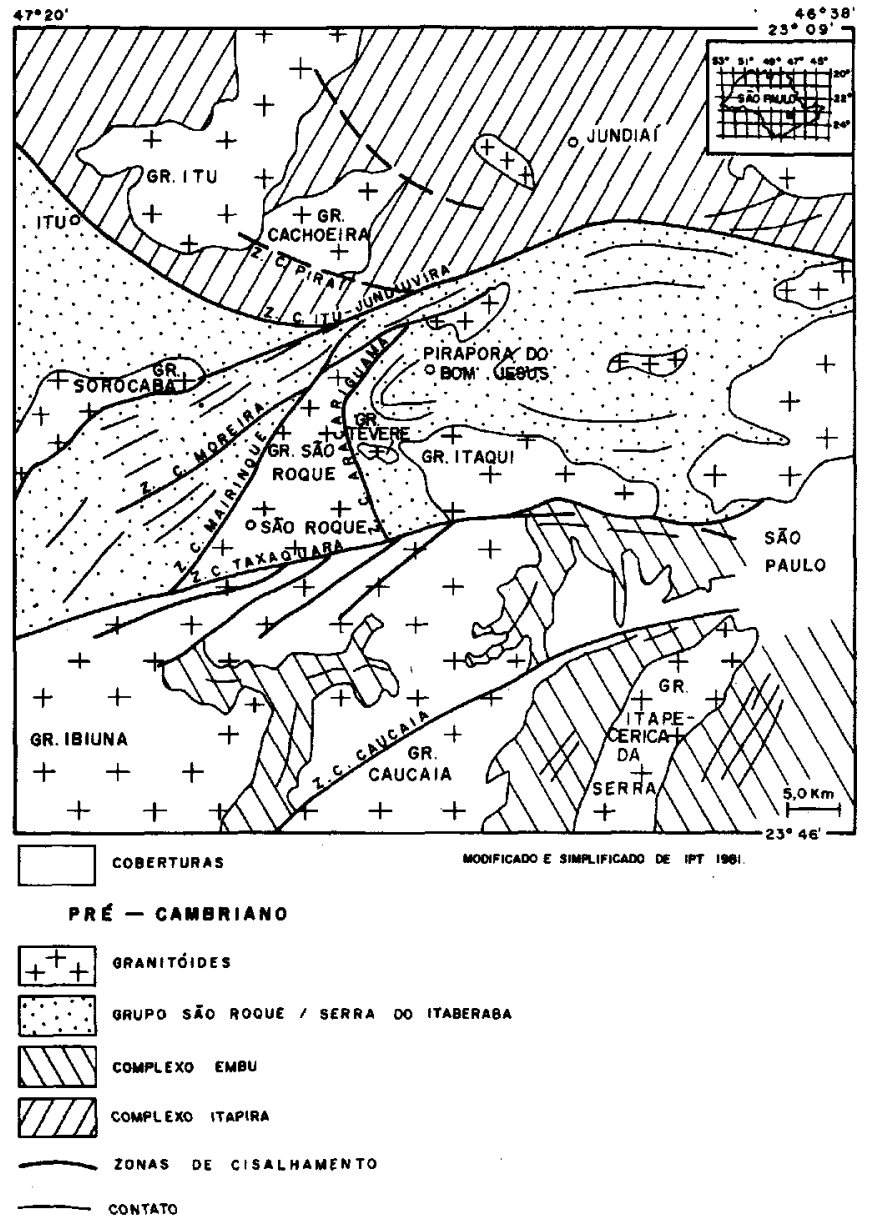

Figura 1 -Localização e Mapa Geológico da região de São Roque-SP-Brasil

Figure 1 - Location and geological map of São Roque region-SP-Brazil

mente migmatizados e de distribuição aleatória nas proximidades de Cabreúva - SP. Segue-se a Formação Japi (Hasui et al. 1978), composta predominantemente por quartzitos feldspáticos e muscovita quartzitos, com intercalações subordinadas de gnaisses, rochas calciossilicáticas e anfibolitos. A Formação Japi aflora na serra homônima com extensão oeste ao longo da Serra de Guaxutuba. Sobre a Formação Japi encontramos biotita-granada xistos e granada-biotita gnaisses da Formação Jundiuvira (Hackspacher et-ai. 1992b), localizados a norte e a sul da Serra do Japi. As condições metamórficas provocaram a fusão parcial dos metassedimentos com a formacão de migmatitos tipo schlieren, estromáticos e outros, além de gnaisses graníticos com granada.

Com a distensão da crosta Transamazônica, há aproximadamente 1,8 Ga (Tassinari et al. 1988), teria início a deposição da seqüência vulcanossedimentar referente aos Grupos Serra do Itaberaba e São Roque, seguida de evolução tectono-metamórfica durante o Ciclo Brasiliano (Tassinari 1988), com a possibilidade de evento orogênico no Proterozóico Médio (Tassinari et al 1985).

Os Grupos Serra do Itaberaba e São Roque encontram-se no Bloco São Roque entre os blocos Jundiaí e Embú. A delimitação destes blocos é dada pelas Zona de Cisalhamento Itu - Jundiuvira (ZCIJ), a norte, e a Zona de Cisalhamento Taxaquara (ZCTa), a sul (Hasui et al 1969).

O Grupo Serra do Itaberaba foi reconhecido, na região, como basal ao Grupo São Roque, inicialmente por Juliani et al (1986) e Hackspacher et al (1992a), devido ao contraste litológico observado entre as unidades metassedimentares de ambos os grupos. Juliani et al (1986) fazem uma correlação entre os metassedimentos em fácies anfibolito da localidade tipo Serra do Itaberaba com os litotipos encontrados entre os Granitos São Roque e Itaqui, assim como com os metassedimentos em torno do Maciço São Roque. Apesar de não haver dados disponíveis sobre a idade deste grupo, acredita-se que sua sedimentação não deva fugir do valor de 1,8 Ga, semelhante ao do Grupo São Roque.

O Grupo São Roque é encontrado no centro da Folha Cabreúva, entre as zonas de cisalhamento Itu-Jundiuvira e Taxaquara. Essas zonas de cisalhamento dão o caráter de discordância tectônica com as unidades do Complexo Itapira e Embu.

No Grupo São Roque, são descritos metassiltitos e metarritmitos pelíticos da Formação Estrada dos Romeiros, quartzitos da Formação Voturuna e metacalcários e metabásicas da Formação Pirapora (Bergmann 1988). Os metarritmitos, filitos, metassiltitos, metarenitos feldspáticos finos e grossos mostram uma interestratifícação, localmente com granules e seixos. O metarritmito predomina na Formação Estrada dos Romeiros, passando subordinadamente para filitos e metassiltitos. Está organizado em forma de ciclos gradacionais, granodecrescente ascendente, de espessura milimétrica e métrica, mais freqüentemente centimétrica e decimétrica, dando ao conjunto o aspecto de alternância entre granulação fina e grossa. Tais unidades são consideradas como depositadas no Proterozóico Médio/Inferior, com idade de 1,8 Ga determinada em metavulcânicas intermediárias no Morro do Polvilho (Van Schmus et al 1986).

As Suítes Graníticas foram colocadas no final do Proterozóico Superior (Tassinari 1988). Considerando a complexa evolução destes corpos granitóides, descrevese inicialmente o Granito Tévere, intrusive no Grupo Serra do Itaberaba e estando intensamente deformado e afetado pela foliação $\mathrm{Sn}+1 /+2$. Sincrônico a $\mathrm{Dn}+3$ temos os maciços de São Roque e Sorocaba (sin-colisionais e transcorrentes).

As rochas encaixantes de ambos os maciços apresentam auréolas de metamorfismo de contato, caracterizadas pelo desenvolvimento de porfiroblastos de biotita, andalusita, cordierita, corindon e feldspato potássico, representando, nas zonas marginais, paragêneses da fácies piraxênio hornfels e nas zonas mais externas hornblenda hornfels e albita hornfels. No Maciço Sorocaba as rochas cornubianíticas estão mais preservadas, enquanto no Maciço São Roque ocorrem localizadamente em decorrência das modificações superimpostas pelos contatos dominantemente tectônicos. O posicionamento dos granitóides São Roque e Sorocaba, sincrônico à fase $\mathrm{Dn}+3$, é evidenciado pelo crescimento de porfiroblastos na $\mathrm{Sn}+3$.

O Maciço Sorocaba é composto dominantemente por associações monzograníticas a sienograníticas e localmente granodioríticas, com tendência cálcio-alcalina de médio a alto potássio, peraluminosa, sendo classificado como granito de alta profundidade (série 4c), com base em dados de tipologia do zircão (Pupin 1980 apud Godoy \& Figueiredo 1991), com temperatura de cristalização da ordem de 800 a $850^{\circ} \mathrm{C}$.

O Maciço São Roque caracteriza-se por associações monzograníticas e, localmente, sienograníticas, arnbas com tendências cálcio-alcalinas de médio potássio, às quais se associam granitóides de características crustais gerados por processos de fusão parcial de metassedimentos ou por meio de processos que envolveram intensa assimilação de rochas encaixantes. Ambos são de caráter peraluminoso, podendo ser classificados segundo a tipologia do zircão (Pupin 1980) como granitos de média (série 4b) e baixa 
(série 4a) profundidade às rochas crustais, com temperatura de cristalização na ordem de 700 a $750^{\circ} \mathrm{C}$. (Godoy et al. 1992).

Foi descrito na área a norte do Granito São Roque um corpo granítico, denominado de Pica-Pau (Oliveira et al 1992), com composição predominantemente sienogranítica semelhante à do Granitóide São Roque. O mesmo era desconhecido na literatura geológica, provavelmente devido a sua localização na ramificação das Zona de Cisalhamento Itu Jundiuvira e Mairinque, estando portanto extremamente tectonizado.

As suítes granitóides tardi-tectônicas estão caracterizadas à norte da área pelo Maciço Itu e ocorrendo próximo e a leste deste o Maciço Cachoeira que representa provavelmente fácies isoladas do Maciço Itu (Fig.l), no domínio do Complexo Itapira.

A história deformacional/metamórfica é reconhecida por uma deformação Dn-1/Dn (Hackspacher et al. 1991a), mais antiga, e somente encontrada nos metassedimentos e ortoderivadas do Complexo Itapira, com foliação de baixo ângulo e transporte para NW (Oliveira et al. 1992), acompanhada por metamorfismo em fácies anfibolito médio a alto, durante o Ciclo Transamazônico (Artur 1988). Discordantemente das fases anteriores, tem-se as deformações Dn+1, Dn+2 (Carneiro 1983, Bistrichi 1984, Hackspacher et al 1991a), associadas à Orogênese Brasiliana, com formação de dobras invertidas a recumbentes e foliação suborizontal associada a provável transporte para SE. Para os Grupos Serra do Itaberaba e São Roque, foi caracterizado o metamorfismo $\mathrm{Mn}+1 /+2$, sendo que no Grupo Serra do Itaberaba em níveis mais profundos, as paragêneses atingem a fácies xistos verdes alto e anfibolito baixo, com presença nas rochas metabásicas de epídoto e actinolita junto à hornblenda e, em rochas pelíticas, granada. O Grupo São Roque é caracterizado basicamente por rochas na fácies xistos verdes baixo-médio, com a presença em rochas pelíticas de clorita e biotita, e em metabásicas da associação actinolita-epidotoalbita. Acredita-se que esta tectônica tenha atuado inicialmente sobre os metassedimentos do Grupo Serra do Itaberaba, tendo evoluído progressivamente, e com taxas de deformações menores, para os metassedimentos do Grupo São Roque.

Segue-se a fase $\mathrm{Dn}+3$ com formação de dobras normais de foliação vertical associada a um metamorfismo na fácies xistos-verdes média regional e metamorfismo de contato em torno dos Maciços Sorocaba e São Roque. Relacionado a esta fase tem-se um regime transtensivo inicial, associado à colocação dos granitos brasilianos, seguido de regimes transcorrente/transpressivos, com formação de milonitos numa tectônica dúctil-rúptil. A partir da Zona de Cisalhamento Itu-Jundiuvira e da Zona de Cisalhamento Taxaquara, desenha-se um verdadeiro leque de zonas de Cisalhamento com ramificações para NW-SE, através da Zona de Cisalhamento Piraí (ZCPi), NE-SW dada pela Zona de Cisalhamento Mairinque (ZCMa) e Zona de Cisalhamento Moreira (ZCMo) e curviplanar, dada pela Zona de Cisalhamento Araçariguama (ZCAr). O final da ascensão de magmas e a atual estruturação dos corpos graníticos estão relacionados principalmente com estas zonas de Cisalhamento.

Junto aos maciços São Roque e Sorocaba, estão expostos, através de contato tectônico gerado pela fase $\mathrm{Dn}+3$, os xistos do Grupo Serra do Itaberaba, portadores de granada formadas em $\mathrm{Mn}+2$. Lateralmente aos corpos granitóides, os xistos gradam para os metapelitos de fácies mais baixa. Tal constatação demonstra um soerguimento de unidades inferiores, em isógrada da granada, dado pela colocação desses maciços (Fig. 2), associado à tectônica transcorrente/transpressiva.

Uma tectônica rúptil mais jovem, com direção NW-SE (Godoy 1989), é ainda caracterizada para a área, pela expo- sição lateral de blocos crustais de profundidades diferentes, observada no Maciço Sorocaba.

CINEMÁTICA NO GRUPO SÃO ROQUE Cinemática de Baixo Ângulo Consideramos a existência de uma deformação $\mathrm{Dn}+1 /+2$ associada ao metamorfismo $\mathrm{Mn}+1 /+2$ em condições de fácies xistos-verdes a anfibolito baixo, afetando tanto as unidades do Grupo Serra do Itaberaba como do Grupo São Roque (Oliveira et al. 1992). Em vários locais, é possível reconhecer estruturas indicativas de encurtamento tectônico no sentido SE e também NW, a exemplo de dobras invertidas com tal vergência, inversão de estruturas em meso escala e feições de estiramento/ encurtamento.

Quanto à intensidade da deformação, há maior penetratividade da foliação nos metassedimentos do Grupo Serra do Itaberaba e menor nos do Grupo São Roque, com as diferenças metamórficas expostas acima. Apesar destas evidências, não foi possível caracterizar discordâncias que permitam diferenciar histórias tectono-metamórficas distintas. As diferenças na intensidade da deformação e no grau metamórfico nos litotipos da base, Grupo Serra do Itaberaba, para o topo, Grupo São Roque, parecem estar muito rnais relacionadas à hipótese de uma evolução progressiva em níveis crustais distintos, na qual a base registra uma deformação mais intensa ou ainda a uma evolução tectono/metamórfica na base seguida de deformação continuada para o topo.

Em ambas as hipóteses, através de uma tectônica de cavalgamento, temos encurtamento crustal progressivo relacionado à fase inicial/intermediária de um evento colisional de subducção do tipo A.

Cinemática de Alto Ângulo A Cinemática de alto ângulo está presente por meio da formação de uma foliação vertical em todas as litologias dos Grupos Serra do Itaberaba/ São Roque, assim como nas unidades mais antigas. Esta foliação grada de um caráter viscoso transtensional, nos Maciços São Roque e Sorocaba, até transcorrente/transpressivo de caráter dúctil regional e dúctil/rúptil junto às zonas de Cisalhamento principais.

A história transtensiva inicial é definida através da medida de deformação finita feita no Maciço São Roque em sua porção menos deformada, na qual são reconhecidas feições de orientação e de entelhamento de fenocristais de feldspatos em estado subsólido.

A tectônica transcorrente/transpressiva (Hackspacher et al. 1992c), de caráter dúctil/rúptil, é marcada pela foliação milonítica com direção geral NE/SW, mergulhos altos para NW ou SE e lineação de estiramento/encurtamento suborizontal, com direção NE-SW. A progressividade do evento milonítico é reconhecida em escala regional pelo seccionamento das Zonas de Cisalhamento Araçariguama, Moreiras e Mairinque pela Zona de Cisalhamento Taxaquara. Nas rochas plutônicas as microestruturas associadas são representadas por alinhamentos de porfiroclastos de feldspato potássico e plagioclásio (lineação de estiramento/encurtamento) de tamanhos diversos em bandas ricas em quartzo, mica branca, biotita verde, albita e, localmente, epídoto.

Os porfiroclastos mostram-se rotacionados com franjas de pressão assimétricas, indicando sentido de movimento em geral horário para o conjunto das zonas de Cisalhamento, podendo em alguns casos, ser anti-horário. Entre as bandas neoformadas (miloníticas), tem-se leitos quartzosos milimétricos, com recristalização dinâmica $\mathrm{Sm} / \mathrm{Sm}$ ', indicando idêntico sentido de transporte. Bandas milimétricas de biotita verde e mica branca se alternam com o leitos quartzosos, sugerindo processo de transformação dos feldspatos em mica branca em condição de fácies xistos verdes.

Localmente, ocorrem leitos milimétricos de cristais de albita $\left(\mathrm{An}_{10}\right)$ mostrando uma forte relação com mirmequitas 

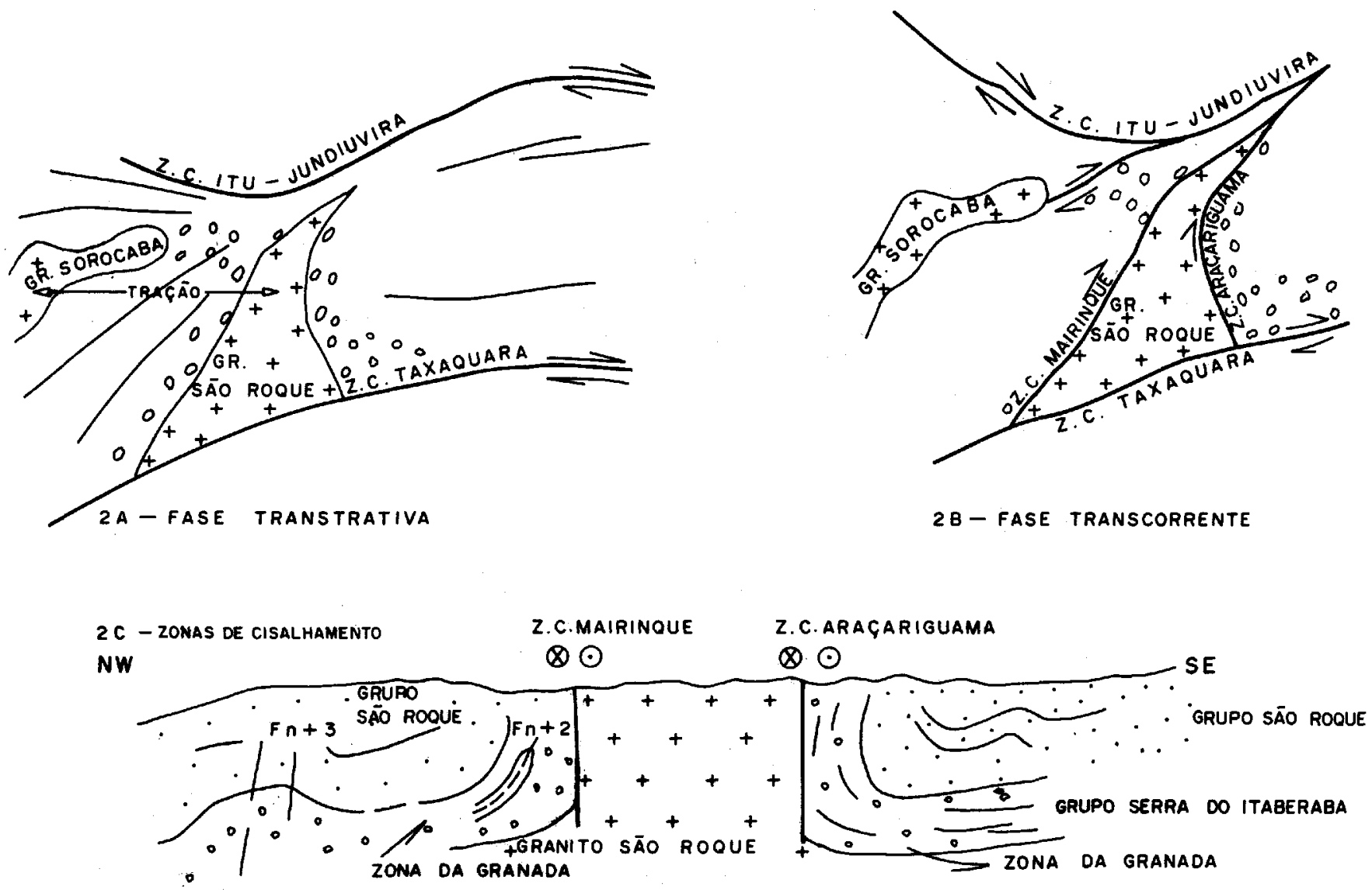

Figura 2 - Esboços e perfil esquemáticos relacionando o alojamento do Maciço São Roque a um regime transtensional (2A) evoluindo para transcorrente/transpressional (2B). O alçamento da isógrada da granada (Mn+2) está associado ao alojamento do Maciço São Roque e ao controle das Zonas de Cisalhamento Mairinque e Araçariguama (2C) Figure 2 - Two geological sketches and a profile to illustrate how the São Roque Massif evolved from a transtensional (2A) to a transcurrent/transpressional $(2 \mathrm{~B})$ regime. The uplift of the garnet isograd $(\mathrm{Mn}+2)$ is related to the emplacement of the São Roque Massif and was influenced by the Mairinque and Araçariguama shear zones $(2 \mathrm{C})$

neoformadas. Estas representam um estágio precoce de cristalização, seguido da formação das bandas ricas em albita (Hackspacher \& Legrand 1989). A ativação de planos cristalográficos dos feldspatos (macia albita-periclina, pertita, translação intracristalina) e quartzo corroboram as condições metamórficas (Hackspacher et al. 1991 b). Tardiamente ocorrem processos de recuperação e annealing em todas as associações minerais, mostrando atenuação das condições metamórficas e caracterizando a história térmica tardia.

Nos metassedimentos, a foliação milonítica se expressa pelo anastomosamento em torno de cristais de feldspatos e quartzo, sendo difícil a diferenciação da clivagem ardosiana regional.

O evento de deformação $\mathrm{Dn}+3$ está basicamente relacionado aos períodos de transcorrência, com regime transtensivo inicial e transpressivo final.

DISCUSSÃO O quadro evolutivo no Grupo São Roque teria ocorrido a partir de uma distensão da crosta Transamazônica, com sedimentação e vulcanismo do Grupo Serra do Itaberaba (Juliani et al. 1986), seguida da deposição de unidades rítmicas distais rasas, siltosas à arenosas, vulcânicas básicas (Figueiredo et al 1982) a ácidas e margosas do Grupo São Roque (Bergmann 1988, Hackspacher et al 1992c), afetadas por deformação e metamorfismo distintos, em razão de níveis crustais de profundidades diferentes.

A evolução tectono-metamórfica é complexa, sendo sugeridos dois pulsos durante o fechamento da bacia. No primeiro, desenvolveram-se as fases $\mathrm{Dn}+1 /+2$ tangenciais, associadas ao início do processo colisional em níveis crustais distintos nos Grupos Serra do Itaberaba e São Roque, com mais intensidade nas unidades basais. Com certa restrição, mencionamos uma sugestão feita por Tassinari et al (1985), na qual haveria um metamorfismo em 1,3 Ga. Progressivamente, temse a formação de estruturas $\mathrm{Dn}+3$, associadas à colocação de corpos plutônicos (São Roque e Sorocaba), sin-colisionais a sin-transcorrentes (Hackspacher et al 1991c) entre 0,8 e 0,7 Ga (Tassinari 1988) de afinidade cálcio-alcalina, (Godoy 1989 e Godoy et al 1992), originada pela fusão da crosta continental inferior. Por meio de feições ígneas, da análise de deformação feita nas fraç̃es não deformadas plasticamente, do estudo da morfologia de zircão e do metamorfismo de contato nas rochas de baixo grau do Grupo São Roque, correlaciona-se, neste trabalho, os Maciços São Roque e Sorocaba a eventos transtensionais em crosta inferior a média.

Os granitos ascendem a níveis mais rasos da crosta, chegando a profundidades entre 12 e $15 \mathrm{~km}$ (Pires \& Hackspacher 1989) onde tería-se a milonitização em regime transcorrente/transpressivo e a formação de dobras normais Fn+3 em zonas menos milonitizadas.

A relação entre as dobras $\mathrm{Fn}+3$, o alçamento da isógrada de metamorfismo do Grupo Serra do Itaberaba e a colocação dos Granitos São Roque e Sorocaba mostra que existe uma ascensão de rochas plutônicas passando de regime, loca-lizadamente, transtensional para um campo compressional de caráter regional, na crosta superior. 
$\mathrm{Na}$ faixa de ocorrência do Grupo São Roque, faltam os granitos com registro de uma tectônica $\mathrm{Fn}+3$ de baixo ângulo, com sentido de transporte para norte, a exemplo dos Granitos Ibiúna, Socorro e Nazaré Paulista. Esta tectônica de baixo ângulo está relacionada às rampas laterais das transcorrências Brasilianas e não deve ser confundida com as foliações de baixo ângulo de transporte NW encontradas em outros locais do pré-cambriano paulista e sudeste brasileiro, relacionadas à fase principal de colisão continental (Hackspacher et al. 1992c).

A estruturação em blocos NE-S W, responsável pela colocação lateral dos blocos Jundiaí, São Roque, Embú etc., seria resultado da história transpressiva final, tardi-transcorrência de $\mathrm{Dn}+3$.
Rochas plutônicas subalcalinas, a exemplo do Maciço Itu, cortam os milonitos brasilianos, mostrando uma história tensional/transtensional posterior.

Agradecimentos Ao CNPq (Conselho Nacional de Desenvolvimento Científico e Tecnológico) (Proc. 50.0863/90-3 e 500.880/91-3) e ao PADCT/FINEP (Programa de Apoio ao Desenvolvimento Científico e Tecnológico/Financiadora de Estudos e Projetos do MCT) (Convênio 6.5.92.0040.00), nossos agradecimentos pelos financiamentos concedidos. Agradecimentos vão aos relatores anônimos pelas críticas e sugestões construtivas.

\section{REFERÊNCIAS BIBLIOGRÁFICAS}

ARTUR A.C. 1988. Evolução Policfclica da Infra-Estrutura da Porção Sul do Estado de Minas Gerais e Regiões Adjacentes do Estado de São Paulo. São Paulo. 231 p. (Tese de Doutoramento, IG-USP).

BATISTA, J.J.; SIMÕES, L.S.A.; OLIVEIRA, M.A.F.; SOUZA FILHO, E.E. 1986. Folha de Jundiai-Carta Geológica do Estado de São Paulo 1:50 000. São Paulo, Conv. IGCE/UNESP/PRÓ-MINÉRIO. 124 p. (Rei. Final 1). (Inédito).

BERGMANN, M. 1988. Caracterização Estratigráfica e Estrutural da Seqüencia Vulcano-Sedimentar do Grupo São Roque, na região de Pirapora do Bom Jesus - SP. São Paulo. 167 p. (Dissertação de Mestrado, IG-USP)

BISTRICHI, CA. 1984. Geologia do Sinclinório de Pirapora, SP. São Paulo. 126 p. (Dissertação de Mestrado, IG-USP).

CARNEIRO, C.D.R. 1983. Análise Estrutural do Grupo São Roque na Faixa entre o Pico do Jaraguá e a Serra dos Cristais, São Paulo. São Paulo. 155 p. (Tese de Doutoramento, IG-USP).

FIGUEIREDO, M.C.H.; BERGMANN, M.; PENALVA, R; TASSINARI, C.C.G. 1982. Ocorrência de "Pillow Lavas" no Grupo São Roque, Estado de São Paulo. Ciências da Terra, 2:6-8.

GODOY, A.M. 1989. Caracterizacãa Faciológica, Peírográfica e Geoquímica dos Maciços Sorocaba e São Francisco. São Paulo. 221 p. (Tese de Doutoramento, IG-USP)

GODOY, A.M. \& FIGUEIREDO, M.C.H. 1991. Caracterização Faciológica e Petrográfíca do Maciço Granitóide Sorocaba (SP). In: SIMP. GEOL. SUDESTE, 2. São Paulo, 1991. Atas... São Paulo, SBG/NSP-NRJ. v. 2, p. 31-138.

GODOY, A.M.; ZANARDO, A.; ARTUR, A.C.; OLIVEIRA, M.A.F.; MORALES N.; HACKSPACHER, P.C.; GALEMBECK, T.M.B. 1992. Rochas Granitóides da Folha São Roque-SP. In: CONOR. BRÁS. GEOL., 37. São Paulo, 1992. Anais... São Paulo, SBG. v. 2, p. 356-357.

HACKSPACHER, P.C.; WERNICK, E.; OLIVEIRA, M.A.F.; GODOY, A.M.; VALERIANO, C.M.; GALEMBECK, T.M.B.; ANGELI, R; ZANARDO, A.; FÚLFARO, V.J.; LEITE JUNIOR, W.B.; ARTUR, A.C. 1988. Geologia das Folhas Cabreúva e Moreira 1:25.000. São Paulo, Conv. IGCE/UNESP/PRÓ-MINÉRIO. 94 p. (Rei. Final 1). (Inédito).

HACKSPACHER, PC. \& LEGRAND, J.M. 1989. Deformation and metamorphism on the Portalegre Shear Zone, Northeastern Brazil. Rev. Bras. Geoc., 19:63-75.

HACKSPACHER, P.C.; GODOY, A.M.; OLIVEIRA, M.A.F. 1991a. Tectônica transcorrente e de cavalgamento do sistema de cisalhamento do Sudeste Brasileiro In: SIMP. NAC. EST. TECT., 3. Rio Claro, 1991. Boletim... Rio Claro, SBG/NSP. v. 1, p. 223-230.

HACKSPACHER, P.C.; GODOY, M.L.S.; SANTOS, E.L. 1991b. Petrotrama de quartzo e feldspato ao longo da Zona de Cisalhamento de Jundiuvira, Cabreúva - SP. In: SIMP. NAC. EST. TECT., 3. Rio Claro, 1991. Boletim... Rio Claro, SBG. v. 1, p. 119-121.

HACKSPACHER, P.C.; OLIVEIRA, M.A.F.; GODOY, A.M. 1991c. Controle do nível metamórfico e da disposição dos corpos granitóides pela tectônica Dn+3/Transcorrente na Folha Cabreúva. In: SIMP. GEOL. SUDESTE, 2. São Paulo, 1991. Atas... São Paulo, SBG/NSP-NRJ. v. 1, p. 151-154.

HACKSPACHER, P.C.; GODOY, A.M.; OLIVEIRA, M.A.F. 1992a. Geologia da Folha Pirapora, SP, em 1:25.000. In: CONOR. BRAS. GEOL., 37. São Paulo, 1992. Boletim de Resumos Expandidos... São Paulo, SBG. v. 2, p. 127-128.

HACKSPACHER, P.C.; OLIVEIRA, M.A.F; GODOY, A.M. 1992b. Geologia dos Grupos Serra do Itaberaba/São Roque na Folha Cabreúva -
SP, em 1:50.000, In: CONOR. BRAS. GEOL., 37. São Paulo, 1992. Anais... São Paulo, SBG-NSP. v. 2, p. 124-125.

HACKSPACHER, P.C.; MORALES, R; ZANARDO, A.; GODOY, A.M.; OLIVEIRA, M.A.F; ARTUR, A.C. 1992c. A Tectônica Transcorrente-Transpressiva Brasiliana da Folha São Roque-SP. In: CONGR. BRÁS. GEOL., 37. São Paulo, 1992. Anais... São Paulo, SBG/NSP. v. 2, p. 348-349.

HASUI, Y.; PENALVA, F; HENNIES, W.T. 1969. Geologia do Grupo São Roque. In: CONGR. BRÁS. GEOL., 23. Salvador, 1969. Anais... Salvador, SBG. v. 1. p. 101-134.

HASUI, Y; TOGNON, A.A.; SOARES, L. CORDANI, S.M. 1978. Geologia e Tectônica da Serra do Japi. Boi. IG-USP, 9:17-24.

INSTITUTO DE PESQUISAS TECNOLÓGICAS DO ESTADO DE SÃO PAULO 1981. Mapa Geológico do Estado de São Paulo. Escala 1:500.000. São Paulo, IPT. (Monografia 6, 2 v).

JULIANI, C.; BELJAVSKIS, P.; SCHORSCHER, H.D. 1986. Petrogênese do vulcanismo e aspectos metalogenéticos associados: Grupo Serra do Itaberaba na região de São Roque - SP. In: CONGR. BRÁS. GEOL., 34. Goiânia, 1986. Anais... Goiânia, SBG. v. 2, p. 730-747.

NEVES, B.B.B. \& CORDANI, U.G. 1991. Tectonic evolution of South America during the Late Proterozoic. Precabrían Res., 53(1/2):23-40.

OLIVEIRA, M.A.F; MORALES, N.; FÚLFARO, V.J.; SOUZA FILHO, E.E.; CAMPOS, E.G.; GODOY, A.M.; SIMÕES, L.S.A.; RUEDA, J.R.J.; BATISTA, J.J.; ANGELI, N. 1986. Geologia da Quadrícula de Atibaia. 2- Jornada sobre a Carta Geológica do Estado de São Paulo em 1:50 000. São Paulo, Conv. IGCE/UNESP/PRÓ-MINÉRIO/IPT.96p. (Rei. Final 1).

OLIVEIRA, M.A.F.; HACKSPACHER, P.C.; GODOY, A.M. 1992. Geologia da Folha Japi-SP, em 1:25.000. In: CONGR. BRÁS. GEOL., 37. São Paulo, 1992. Anais... São Paulo, SBG. v. 2, p. 129-130.

PIRES, L.C.G. \& HACKSPACHER, PC. 1989. Análise de inclusões fluidas na Zona de Cisalhamento Itu, na região de Cabreúva - SP. In: SIMP. GEOL. SUDESTE, 1. Rio de Janeiro, 1989. Anais... Rio de Janeiro, SBG/NRJ/NSP, v. 2, p. 117-118.

PUPIN, J.P. 1980. Zircon and granite petrology. Contrlb. Mineral. Petrol., 73:207-220.

SANTORO, E. 1984. Geologia da Folha de Cabreúva, SP. São Paulo. 114 p. (Dissertação de Mestrado, IG-USP).

TASSINARI, C.C.G. 1988. A Idade das Rochas e dos Eventos Metamórficos da Porcão Sudeste do Estado de São Paulo e sua Evolução. São Paulo. 236 p. (Tese de Doutoramento, IG-USP).

TASSINARI, C.C.G.; KAWASHITA, K.; KIKUCHI, R.K.P. 1985. Estudo geocronológico nos metaconglomerados do Grupo São Roque, no Estado de São Paulo. In: SIMP. REG. GEOL., 5. São Paulo, 1985. Atas... São Paulo, SBG/NSP. v. 1, p. 201-208.

TASSINARI, C.C.G.; KAWASHITA, K.; VAN SCHMUS, W.R.; TAYLOR, P.N 1988. As idades das rochas e dos eventos metamórficos da região sudeste do Estado de São Paulo. In: CONGR. BRÁS. GEOL., 35. Belém, 1988. Anais... Belém, SBG. v. 6, p. 2840-2853.

VAN SCHMUS, W.R., TASSINARI, C.C.G.; CORDANI, V.G. 1986. Estudos geocronológicos da parte inferior do Grupo São Roque. In: CONGR. BRÁS. GEOL., 34. Goiânia,1986. Anais... Goiânia, SBG. v. 3, p. 1399-1406.

MANUSCRITO A783 Recebido em 31 de agosto de 1993 Revisão do autor em 7 de outubro de 1994 Revisão aceita em 25 de outubro de 1994 